\title{
In Vitro Evaluation of Desensitizing Agents Containing Bioactive Scaffolds of Nanofibers on Dentin Remineralization
}

\author{
Natália Bastos-Bitencourt ${ }^{1}\left(\mathbb{D}\right.$, Marilia Velo ${ }^{1}$ (D), Tatiana Nascimento ${ }^{2,3}$, Cassiana Scotti ${ }^{1}$, \\ Maria Gardennia da Fonseca ${ }^{2}{ }^{\oplus}$, Luiz Goulart ${ }^{3} \oplus$, Lucio Castellano $\left.^{4}{ }^{(}\right)$, Sergio Ishikiriama ${ }^{1}$, Juliana Bombonatti ${ }^{1}$ \\ and Salvatore Sauro $5,6, * \mathbb{D}$
}

Citation: Bastos-Bitencourt, N.; Velo, M.; Nascimento, T.; Scotti, C.; da Fonseca, M.G.; Goulart, L.; Castellano, L.; Ishikiriama, S.; Bombonatti, J.; Sauro, S. In Vitro Evaluation of Desensitizing Agents Containing Bioactive Scaffolds of Nanofibers on Dentin Remineralization. Materials 2021, 14, 1056. https://doi.org/10.3390/ ma14051056

Academic Editor: Andrea Spagnoli

Received: 31 January 2021

Accepted: 19 February 2021

Published: 24 February 2021

Publisher's Note: MDPI stays neutral with regard to jurisdictional claims in published maps and institutional affiliations.

Copyright: (c) 2021 by the authors. Licensee MDPI, Basel, Switzerland. This article is an open access article distributed under the terms and conditions of the Creative Commons Attribution (CC BY) license (https:// creativecommons.org/licenses/by/ $4.0 /)$.
1 Department of Operative Dentistry, Endodontics and Dental Materials, Bauru School of Dentistry, University of Sao Paulo, Bauru, SP 17011-220, Brazil; nembastos@hotmail.com (N.B.-B.); mariliavelo@yahoo.com.br (M.V.); cassikoch@hotmail.com (C.S.); serginho@usp.br (S.I.); julianafraga@usp.br (J.B.)

2 Center for Fuels and Materials (NPE-LACOM), Program of Post-Graduation in Chemistry, Federal University of Paraíba (PPGQ-UFPB), João Pessoa, PB 58033-455, Brazil; tatirln@hotmail.com (T.N.); mgardennia@gmail.com (M.G.d.F.)

3 Laboratory of Nanobiotechnology (NANOS), Institute of Biotechnology, Federal University of Uberlândia, Av. Pará, 1720, Uberlândia, MG 38400-902, Brazil; lrgoulart@ufu.br

4 Human Immunology Research and Education Group (GEPIH), Technical School of Health, Federal University of Paraíba, João Pessoa, PB 58059-900, Brazil; luciocastellano2@gmail.com

5 Dental Biomaterials and Minimally Invasive Dentistry, Department of Dentistry, Cardenal Herrera-CEU University, CEU Universities, C/Santiago Ramón y Cajal, s/n., Alfara del Patriarca, 46115 Valencia, Spain

6 Department of Therapeutic Dentistry, I.M. Sechenov First Moscow State Medical University, 119146 Moscow, Russia

* Correspondence: salvatore.sauro@uchceu.es; Tel.: +34-961-369-000

\begin{abstract}
This study evaluated the effect of the incorporation of bioactive nanofibers in desensitizing agents on dentin permeability. Sixty disks of dentin were randomly distributed in four groups $(n=15)$. Distribution was based on the desensitizing agents, fluoride varnish and self-etching adhesive, and the presence of nanofibers: C (self-etching adhesive Clearfil SE Bond), CN (Clearfil SE Bond with 1\% nanofiber), D (Duraphat varnish), and DN (Duraphat varnish with 1\% nanofiber). Dentin permeability was determined using hydraulic conductivity. For a qualitative analysis, confocal laser microscopy and scanning electron microscopy were performed. The $\mathrm{C}$ group showed the lowest hydraulic conductance (Lp\%) (89.33), while the DN group showed the highest Lp\% (116.06). No statistical significance was observed in the $\mathrm{Lp} \%$ values in all groups after the treatment and $6 \%$ citric acid challenge $(p>0.239)$. In the images, the $\mathrm{CN}$ group presented a higher superficial and intratubular deposition. In addition, this group presented a more homogeneous dentin surface and wide occlusion of dentinal tubules than the other treatments. Despite there being no statistical differences among the treatments employed, the images showed that the $\mathrm{CN}$ group presented a higher surface and intratubular deposition compared to the other treatments, even after the acid challenge.
\end{abstract}

Keywords: dentin hypersensitivity; sensitivity; therapy; nanofibers; hydroxyapatites

\section{Introduction}

Dentin hypersensitivity (DH) can be classified as a pain symptom arising from exposed dentin, associated or not to noncarious cervical lesions, in response to thermal, mechanical, osmotic, and chemical stimuli [1]. DH is a common clinical condition, with $74 \%$ prevalence in the general population [2]. Furthermore, it is likely to be a more frequent dental complaint in the next years owing to the increase in the longevity of dentition [3]. Although pain occurs for a short duration, it is sharp and negatively affects the quality of life of patients [3].

One of the most accepted hypotheses for the mechanism of $\mathrm{DH}$ is the hydrodynamic theory reported by Brännström and Aström in 1967 [4]. Under DH, the dentinal tubules are 
frequently open, leading to an increased dentin permeability. The hydrodynamic theory has shown that even a partial reduction in the functional radii of the dentinal tubules will lead to a reduction in fluid flow, thereby reducing pain symptoms [5].

The management of DH has been focused on analgesia caused by obliteration of dentinal tubules [6], mainly using desensitizing agents [7]. However, the instability of dentinal tubule occlusion and recurrence of hypersensitivity may result in desensitizing agents being a palliative solution for painful symptoms. One of the major drawbacks of the desensitizing agents is the requirement of at least $2-4$ weeks to relieve DH symptoms [8]. Therefore, the development of more effective therapies is required considering their longterm performance.

Adhesive systems seem to exhibit a more long-term effect because they create a layer that mechanically blocks the exposed dentinal tubules. These systems include the use of topical fluoride $(\mathrm{F})$ varnishes by precipitating calcium fluoride $\left(\mathrm{CaF}_{2}\right)$ and thus, decreasing dentinal permeability hypersensitivity [9]. F varnishes have shown clinical effectiveness [10]; however, they require multiple applications to take effect because most of the $\mathrm{F}$ ions are released within two weeks [11]. This occurs because $\mathrm{CaF}_{2}$ precipitates are formed on the outer dentin and could be washed away by saliva or toothbrushing, thereby reopening the dentinal tubules and triggering hypersensitivity. However, although not a definitive treatment, the application of dentin adhesive products can block dentin tubules as a semi-invasive technique in more severe cases [12] because the composites can effectively seal the dentinal tubules by forming a hybrid layer [13].

Advances in nanotechnology have also led to the development of bioactive products for hypersensitivity by introducing compounds that form insoluble precipitates. Silica $\left(\mathrm{SiO}_{2}\right)$-containing bioactive glasses and calcium phosphate-based bioceramics have been extensively used in the treatment of $\mathrm{DH}$ [14]. $\mathrm{SiO}_{2}$-based bioactive glasses can nucleate a hydroxyapatite (HAP)-like layer as a product of the chemical reaction between their surface and saliva, thereby occluding the exposed dentinal tubules and reducing the driving of the hydrodynamic stimuli [15]. Bioactive glass particles are shown to be promising in the long-term management of $\mathrm{DH}$; however, in the oral cavity, they can be washed away by the saliva, exposure to an acid challenge, or by toothbrushing [7]. This limits their effects if applied in a coating method. Therefore, novel drug-delivery systems with improved mechanical resistance through an acid challenge would be highly desirable in the field of dental materials.

In tissue engineering, scaffolds of nanofibers are promising biomaterials for regeneration applications because they can impart bioactivity and act as a platform for therapeutic ion release, including different configurations such as 3D scaffolds [16], nanofiber blankets [17], microspheres [18] films/membranes, and foams [19]. Scaffolds of nanofibers have promising characteristics because they combine the desirable properties of the inorganic phase with those of the organic phase and can effectively improve the mechanical properties of dental materials, as shown in a previous study [20]. Moreover, they can induce apatite deposition in a biomimetic delivery system [21].

As calcium phosphate is the main component of dentin, the incorporation of a hybrid nanofiber composed of $\mathrm{SiO}_{2}$ and a stable calcium incorporated in the desensitizing agents appears to be promising for the treatment of DH. Furthermore, it even improves the mechanical resistance of the desensitizing agents through an acid challenge or by forming a more insoluble HAP-like layer. In addition, the remineralizing potential of $\mathrm{SiO}_{2}$ can be enhanced at nanoscale and also provide great adhesion to calcium phosphate due to its increased surface area relative to volume [22-24]. This is a determining factor in HAP formation and might prolong the effect of the desensitizing agent on DH. Hence, the aim of this in vitro study is to evaluate the effect of dentinal tubule occlusion induced by nanofiber scaffolds incorporation (poly lactic acid (PLA) $+30 \%$ silica $+4 \%$ calcium oxide- $\mathrm{CaO}$ ) in an adhesive system and $\mathrm{F}$ varnish, and to investigate their abilities to resist through a new acid challenge. The null hypothesis was that there are no statistical differences in 
hydraulic conductance (Lp) among dentine specimens treated with desensitizing agents with or without the addition of nanofibers.

\section{Materials and Methods}

\subsection{Experimental Design}

Sixty dentin discs were obtained from human third molars and were randomized into four groups $(n=15)$ : C (self-etching adhesive Clearfil SE Bond-positive control), $\mathrm{CN}$ (Clearfil SE Bond with 1\% nanofibers), D (Duraphat varnish-positive control), and DN (Duraphat varnish with 1\% nanofibers). The response variables were a hydraulic conductivity test, confocal laser scanning microscopy (CLSM), and scanning electron microscopy (SEM). For these variables, the dentin surface was analyzed in the following conditions: (T1) in the presence of the smear layer, (T2) after 37\% phosphoric acid etching for $15 \mathrm{~s}$, (T3) after application of the materials tested (Table 1), and (T4) after erosion with $6 \%$ citric acid challenge ( $\mathrm{pH} 1.5)$ for 1 min (Figure 1).

Table 1. Description of brand name, manufacturer, composition, and procedure of all materials used in this study.

\begin{tabular}{|c|c|c|c|}
\hline Material & Manufacturer & Composition & Procedure \\
\hline Clearfil SE Bond & $\begin{array}{c}\text { Kuraray, Sakazu, Kurashiki, } \\
\text { Okayama, Japan }\end{array}$ & $\begin{array}{c}\text { Primer: Water, MDP, HEMA, } \\
\text { hydrophilic dimethacrylates, } \\
\text { camphorquinone. } \\
\text { Bond: MDP, Bis-GMA, HEMA, } \\
\text { camphorquinone hydrophobic } \\
\text { dimethacrylate, N/N-diethanol } \\
\text { p-toluidine bond, colloidal silica. }\end{array}$ & $\begin{array}{l}\text { Apply primer (20 s), and } \\
\text { gently air dry } \\
\text { Apply adhesive, gently air dry, } \\
\text { light cure (10 s) }\end{array}$ \\
\hline Duraphat & $\begin{array}{c}\text { Colgate }^{\circledR}, \text { Sao Bernardo do } \\
\text { Campo, SP, Brazil }\end{array}$ & $\begin{array}{c}1 \mathrm{~mL} \text { of this suspension contains } 50 \mathrm{mg} \\
\text { sodium fluoride, equivalent to } 22.6 \mathrm{mg} \\
\text { fluoride, in an alcoholic solution of } \\
\text { natural resins. }\end{array}$ & Passively apply for $4 \mathrm{~min}$ \\
\hline
\end{tabular}

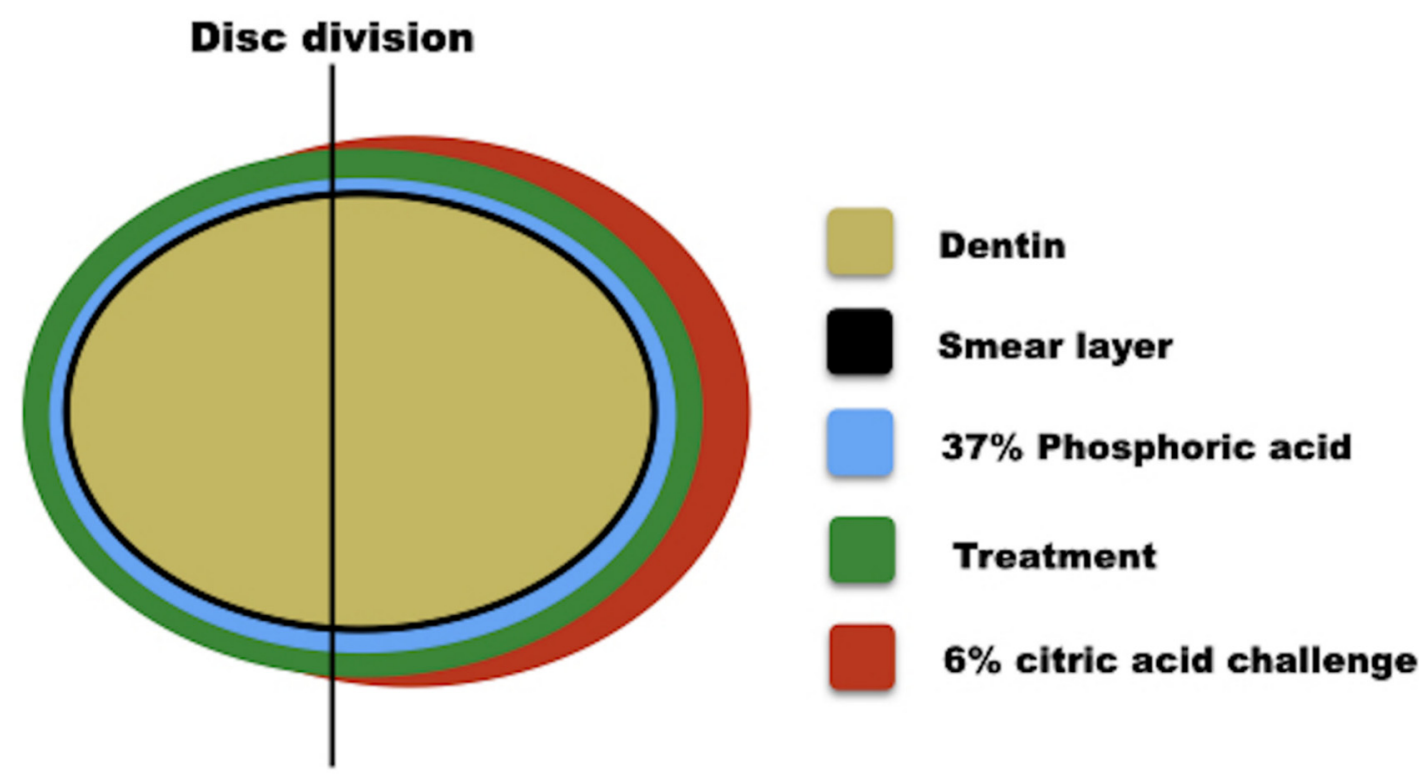

Figure 1. Schematic drawing of the four experimental conditions of the treatment groups.

\subsection{Dentin Sample Preparation}

The human third molars of a healthy adult were collected once informed consent was obtained under a protocol approved by the Ethics Committee of Bauru School of Dentistry, University of Sao Paulo (Protocol/90548918.9.0000.5417). Dentin discs were obtained by 
cutting $4 \mathrm{~mm}$ above the cementoenamel junction with a diamond disc (XL-12205, Extec Corporation, Enfield, CT, USA). These discs had an average thickness of $1 \pm 0.2 \mathrm{~mm}$ and a diameter of $8 \pm 0.5 \mathrm{~mm}$. The specimens were selected by acid-etching with $37 \%$ phosphoric acid for $15 \mathrm{~s}$. The samples were rinsed and the maximum permeability was evaluated, which was assigned a value of $100 \%$ permeability. The dentin discs were randomly divided into four groups $(n=10)$ according to the experimental treatments (Table 1). Before performing the permeability analysis, all the specimens were stored in artificial saliva ( $\mathrm{pH} 7.0)$ composed of $\mathrm{Ca}(1.5 \mathrm{mM}), \mathrm{PO}_{4}(0.9 \mathrm{mM}), \mathrm{KCl}(150 \mathrm{mM})$, and Tris buffer $(20 \mathrm{mM})$ containing NaN $0.02 \%$ [25].

\subsection{Nanofibers Fabrication}

The nanofiber scaffolds were produced by adapted solution blowing and combined air brushing techniques using a set-up described in previous studies [26-29]. The hybrid fibers were produced using a PLA obtained from NatureWorks, Jamplast Inc., Ellisville, $\mathrm{MO}$, USA, in pellet form. Precursor solutions of $\mathrm{SiO}_{2}(30 \%)$ and calcium $(20 \%$ obtained from Gelest PA-USA) were used to develop nanofibers.

\subsection{Adhesive System and Varnish Samples Preparation}

Nanofibers (1 wt.\%) were manually incorporated into the adhesive system and the F varnish by mixing for $10 \mathrm{~s}$. Both the materials and nanofibers were weighed on a precision scale (Denver Instrument, São Paulo, Brazil). The percentage of fibers was determined in a previous study [20] to obtain a material with adequate fluidity. For the adhesive system, a tooth primer was deposited for $20 \mathrm{~s}$ on the dentin discs and thoroughly dried for $5 \mathrm{~s}$ with mild air. A uniform bond film was applied on the dentin discs and light-activated for $10 \mathrm{~s}$ using a light-emitting device (Valo, Ultradent) operating at $1000 \mathrm{~mW} \mathrm{~cm}{ }^{-2}$ at a distance of $1 \mathrm{~mm}$. The varnish was applied using microbrushes (KG Brush, KG Sorensen, Cotia, Brazil), and the excess was removed delicately after $4 \mathrm{~min}$ with a dental explorer. All the specimens were stored in artificial saliva ( $\mathrm{pH}$ 7.0) and were maintained in an incubator at $37^{\circ} \mathrm{C}$.

\subsection{Experimental Conditions}

The response variables were the dentin permeability obtained from the hydraulic conductivity test $(n=11)$ and the qualitative analysis $(n=4)$ of the dentin surface images exposed to the treatments under the following conditions: (T1) in the presence of a smear layer created by an abrasive paper \#600 (Buehler Ltd., Lake Bluff, IL, USA), to obtain the minimum permeability (PMin); (T2) after 37\% phosphoric acid etching for $15 \mathrm{~s}$, to obtain maximum permeability (PMax); (T3) after application of the materials tested (Table 1); and (T4) after erosion with $6 \%$ citric acid challenge ( $\mathrm{pH} 1.5$ ) for $1 \mathrm{~min}$ (final permeability), to simulate clinical conditions (Figure 1).

\subsection{Dentin Permeability Analysis}

Dentin permeability measurements were performed using a Flodec machine (DeMarco Engineering, Geneva, Switzerland) [30]. Each specimen was connected to Flodec using a plexiglass split-chamber device between two rubber O-rings, providing a surface area standardization of $0.282 \mathrm{~mm}^{2}$ under simulated deionized water pulp pressure $\left(20 \mathrm{~cm} \mathrm{H}_{2} \mathrm{O}\right)$. The fluid flow was measured by the movement of an air bubble within a $25 \mathrm{~mL}$ capillary glass. Bubble displacement was recorded for $5 \mathrm{~min}$, and the fluid flow was converted to Lp by dividing the fluid flow $(\mu \mathrm{L} \mathrm{min}-1)$ by the exposed dentin surface area $\left(\mathrm{cm}^{2}\right)$ and the water pressure $\left(\mathrm{cm} \mathrm{H}_{2} \mathrm{O}\right)$. The permeability of each disc was expressed in percentage as $\mathrm{Lp} \%$ and tested under the four conditions, i.e., T1, T2, T3, and T4 (Figure 1).

\subsection{Scanning Electron Microscopy (SEM) Analysis}

The morphologies of the dentinal tubules were evaluated after testing under the four conditions (Figure 1). The specimens $(n=3)$ were subjected to critical point drying and 
were gold coated for SEM (XL30, FEI, Hillsboro, OR, USA) analysis at 10-20 kV [30]. Three photomicrographs were obtained for each condition at $3000 \times$ magnification.

\subsection{Confocal Analysis}

Three-point surface images of the dentin discs $(n=1)$ from each group were obtained by confocal microscopy (Leica TCS SPE, Mannheim, Germany) [31] to identify and compare the dentinal tubule obliteration under 40x magnification, at a depth of $20 \mu \mathrm{m}$. Analyses were performed after the four conditions were applied (Figure 1), since each disc had an occlusal surface delimited with a \#2 spherical carbide drill (KG Sorensen, Sao Paulo, Brazil) in two distinct areas. The materials were applied under the same experimental conditions using hydraulic conductivity. The specimens were divided according to the materials tested, presenting as a control group of discs with a smear layer (minimum permeability) and without a smear layer (maximum permeability). The primary reflection and fluorescence images were overlapped and analyzed on the $\mathrm{XY}$ and $\mathrm{XZ}$ axes.

\subsection{Statistical Analysis}

Statistical analysis was performed using the software SPSS 16.0 (SPSS Inc., Chicago, IL, USA). Dentin permeability was analyzed by two-way analysis of variance (ANOVA) (using treatment and experimental dentin condition values), followed by Tukey's multiple comparison tests. The level of significance was set at 5\% $(p<0.05)$. Qualitative analyses were performed for SEM and confocal images.

\section{Results}

\subsection{Dentine Permeability Measurements}

Dentin permeability (Lp) results are presented as percentages of maximum permeability $(100 \%)$ after $37 \%$ phosphoric acid etching. Table 2 shows the data from the different treatments under four experimental dentin conditions. The two-way ANOVA test showed a significant effect only for the four experimental dentin conditions $(p<0.001)$.

Table 2. Mean and standard deviation of the Lp values (\%) of the different treatments under four experimental dentin conditions $(n=11)$.

\begin{tabular}{|c|c|c|c|c|}
\hline Material & $\begin{array}{l}\text { Minimum } \\
\text { (With Smear Layer) }\end{array}$ & $\begin{array}{c}\text { Maximum } \\
\text { (After Acid Etching) }\end{array}$ & Treatment & $\begin{array}{c}\text { Final } \\
\text { (After Erosive Challenge) }\end{array}$ \\
\hline Clearfil SE Bond C & $\begin{array}{c}55.86 \\
(37.28) \mathrm{Aa}\end{array}$ & $100 \mathrm{Ab}$ & $\begin{array}{c}89.33 \\
(40.56) \mathrm{Aab}\end{array}$ & $\begin{array}{c}87.72 \\
(42.80) \mathrm{Aab}\end{array}$ \\
\hline $\begin{array}{l}\text { Clearfil SE Bond + } \\
\text { nanofiber CN }\end{array}$ & $\begin{array}{l}47.57 \\
(41.23) \mathrm{Aa}\end{array}$ & $100 \mathrm{Ab}$ & $\begin{array}{c}103.35 \\
(28.19) \mathrm{Ab}\end{array}$ & $\begin{array}{c}106.41 \\
(43.13) \mathrm{Ab}\end{array}$ \\
\hline $\begin{array}{c}\text { Duraphat varnish } \\
\text { D }\end{array}$ & $\begin{array}{c}79.19 \\
(46.60) \mathrm{Aa}\end{array}$ & $100 \mathrm{Aa}$ & $\begin{array}{c}106.07 \\
(47.92) \mathrm{Aa}\end{array}$ & $\begin{array}{c}120.61 \\
(65.89) \mathrm{Aa}\end{array}$ \\
\hline $\begin{array}{c}\text { Duraphat varnish + } \\
\text { nanofiberDN }\end{array}$ & $\begin{array}{c}59.79 \\
(27.52) \mathrm{Aa}\end{array}$ & $100 \mathrm{Ab}$ & $\begin{array}{c}116.06 \\
(23.87) \mathrm{Ab}\end{array}$ & $\begin{array}{c}130.86 \\
(32.06) \mathrm{Ab}\end{array}$ \\
\hline
\end{tabular}

Same uppercase letter in column and lowercase letter in line indicates no difference at the $5 \%$ significance level. No statistical significance was observed in the Lp\% values in all the groups after the treatment and $6 \%$ citric acid challenge $(p>0.239)$.

From the $\mathrm{Lp} \%$ values listed in Table 2, it was observed that group $\mathrm{C}$ presented the lowest $\mathrm{Lp} \%$ value for the minimum permeability (55.86) compared to that for the maximum permeability $(p=0.003)$. For the $\mathrm{CN}$ group, the lowest $\mathrm{Lp} \%$ value was found at the minimum permeability (47.57) compared to the other conditions $(p<0.02)$. For the DN group, the lowest $\mathrm{Lp} \%$ value was found at the minimum permeability (59.79) compared to the maximum permeability $(100 ; p=0.008)$ after the treatment $(106.06 ; p=0.003)$ and after the $6 \%$ citric acid challenge $(130.86 ; p=0.003)$. 


\subsection{SEM Evaluation}

Figure 2A shows the obliteration of the dentinal tubules on the surface before etching with $37 \%$ phosphoric acid. After the etching, almost all the dentinal tubules were opened due to the removal of the smear layer. In addition, the peritubular dentin was dense and homogeneous (Figure 2B).
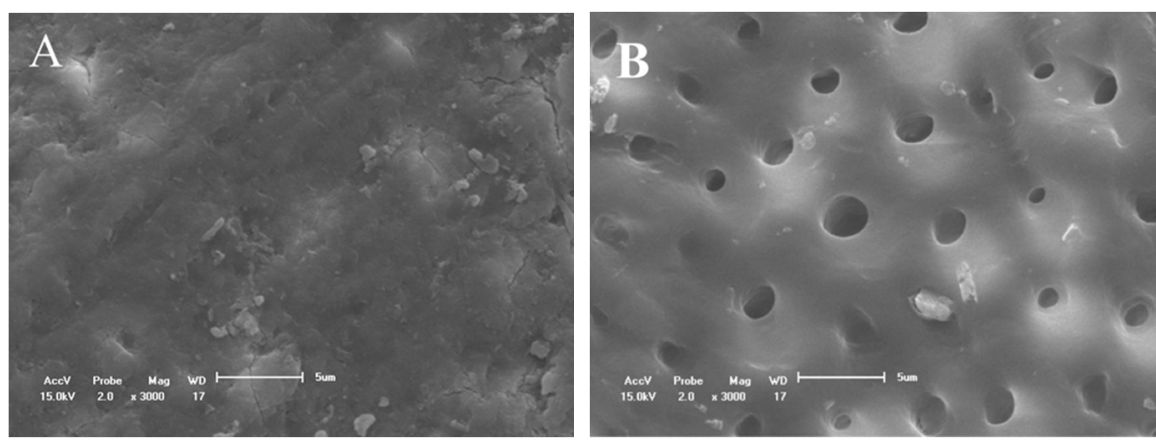

Figure 2. SEM micrographs of the dentine surface morphology at $3000 \times$ magnification. (A) With smear layer and (B) without smear layer. The exposition of dentinal tubules occurred after acid challenge (B).

All the evaluated treatments produced morphological changes in the dentin surfaces (Figures 3-6). For group C, the SEM images showed a wide occlusion of the dentinal tubules (Figure $3 \mathrm{~A}$ ) before the $1 \mathrm{~min}$ of $(6 \%)$ citric acid challenge. However, after the acid challenge, the dentin surface was more porous (Figure 3B). The $\mathrm{CN}$ group showed a more homogeneous and uniform dentin surface with a higher dentinal tubule occlusion as compared to group $C$ (Figure $4 \mathrm{~A}, \mathrm{~B}$ ) before and after the acid challenge.
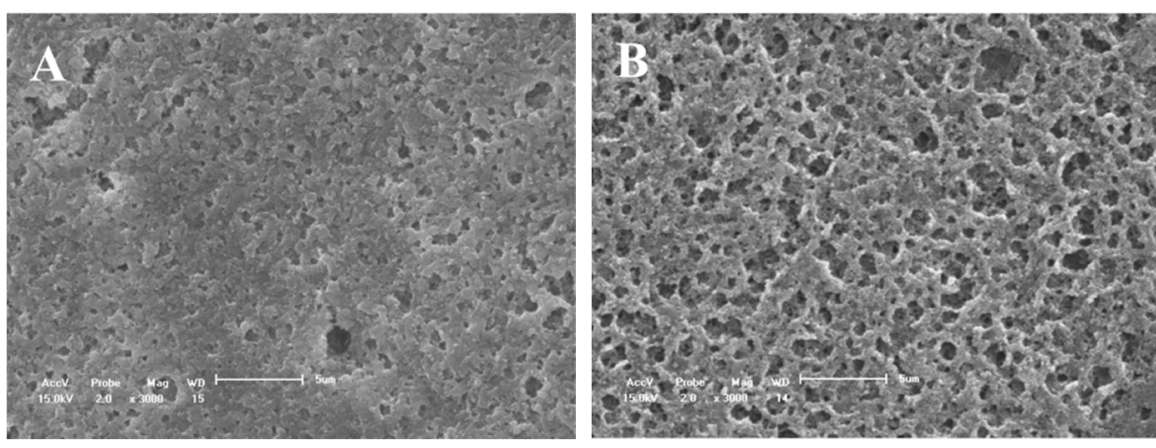

Figure 3. SEM micrographs of the dentine surface morphology at $3000 \times$ magnification. (A) Adhesive without nanofiber and (B) after 6\% citric acid challenge. A more porosity surface was verified in (B).
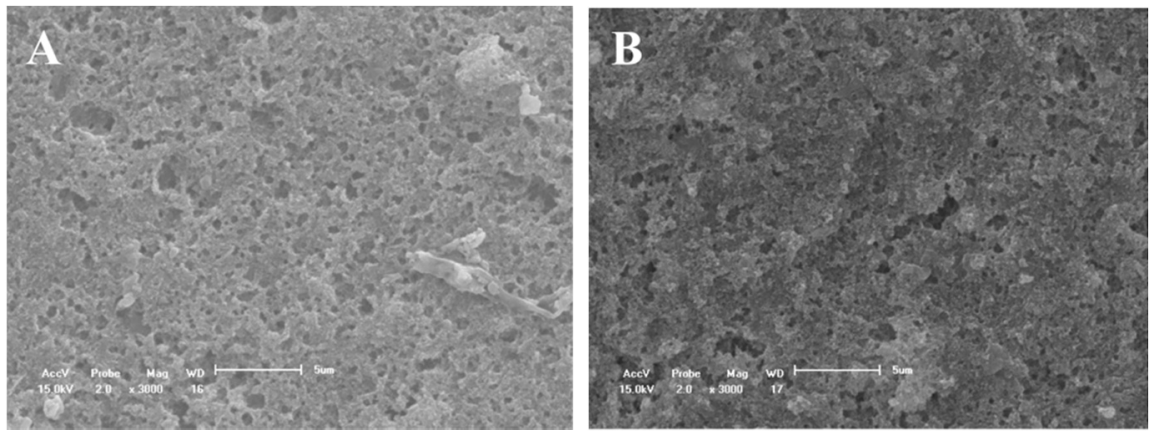

Figure 4. SEM-micrographs of the dentine surface morphology at $3000 \times$ magnification. (A) adhesive with nanofiber and (B) after 6\% citric acid challenge. No changes were observed after acid challenge (B). 

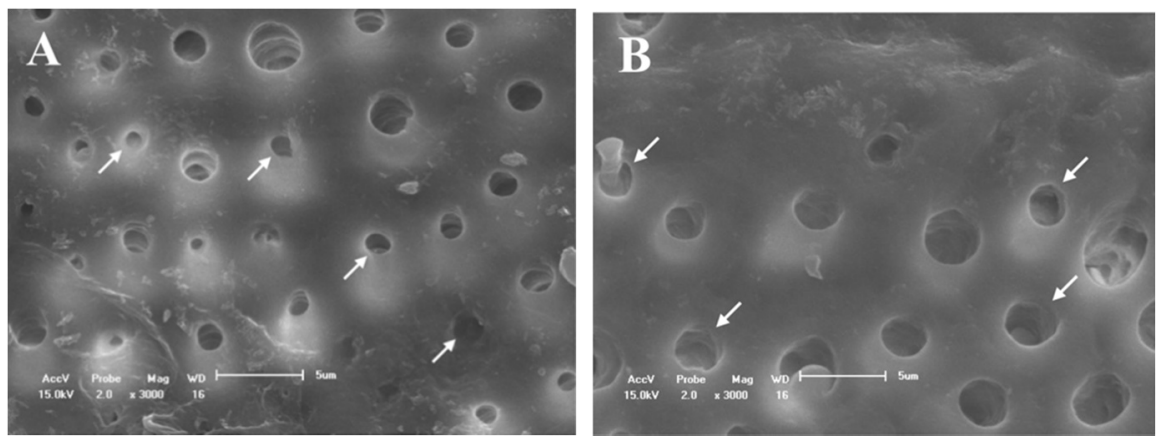

Figure 5. SEM micrographs of the dentine surface morphology at $3000 \times$ magnification. (A) Fluoride varnish without nanofiber and (B) after 6\% citric acid challenge. The arrows indicated the partial tubules occlusion with crystal deposition $(\mathbf{A}, \mathbf{B})$.
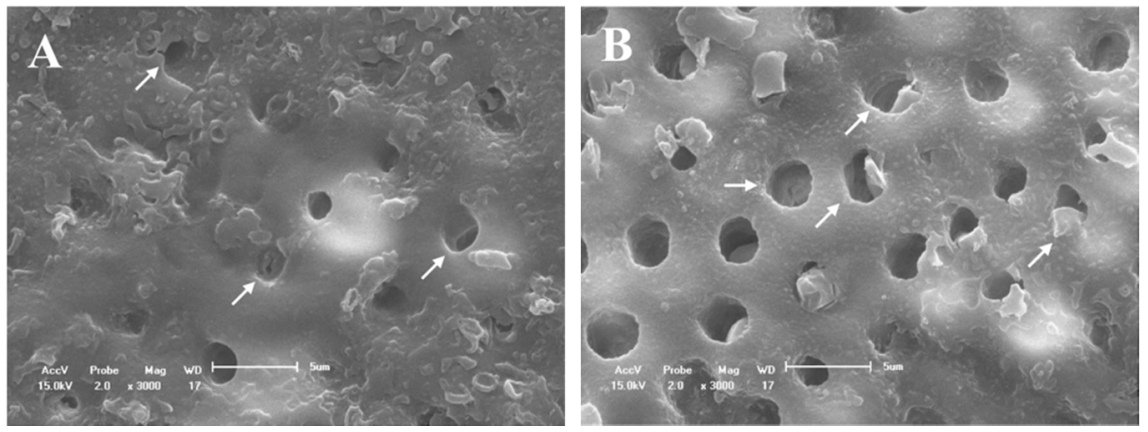

Figure 6. SEM micrographs of the dentine surface morphology at $3000 \times$ magnification. (A) Fluoride varnish with nanofiber and (B) after $6 \%$ citric acid challenge. The arrows indicated the regions with crystals adhered to the dentinal tubules $(\mathbf{A}, \mathbf{B})$.

For group $\mathrm{D}$, the dentinal tubules were partially open, but with a visually smaller diameter (Figure 5A). After the acid challenge, most deposits were removed; however, the tubules were not completely opened, and some deposits were still adhered to the tubule walls (Figure 5B). On the dentin surfaces of the DN group, crystal deposition was observed at the mouth of the dentinal tubules, thus characterizing a partial occlusion of these dentinal tubules (Figure 6A). However, after the acid challenge, the tubules were partially open with crystals adhered to the wall and mouth (Figure 6B). Therefore, a more obliterated dentin surface was observed for group DN as compared to that for group D.

In general, the $\mathrm{CN}$ group had a more homogeneous dentin surface and wide occlusion of dentinal tubules as compared to other treatments.

\subsection{Confocal Evaluation}

The micrographs obtained by confocal microscopy were standardized for all the specimens from all the experimental groups (Figures 7-11). Bright spots can be seen, corresponding to the obstruction of dentinal tubules by the smear layer debris (Figure 7A,B). After etching with $37 \%$ phosphoric acid, the dentinal tubules, which were completely obstructed at the minimum permeability condition (Figure 7B), were partially or completely exposed (Figure 7C,D).

For group $C$, the deposition of the material on a large part of the superficial dentin (Figure 8A) and large particle concentration at the mouth and inside the dentinal tubules were observed before the citric acid challenge, thus characterizing an intratubular obliteration (Figure 8B). After the acid challenge, less superficial (Figure 8C) and intratubular depositions of the material were observed (Figure 8D). 


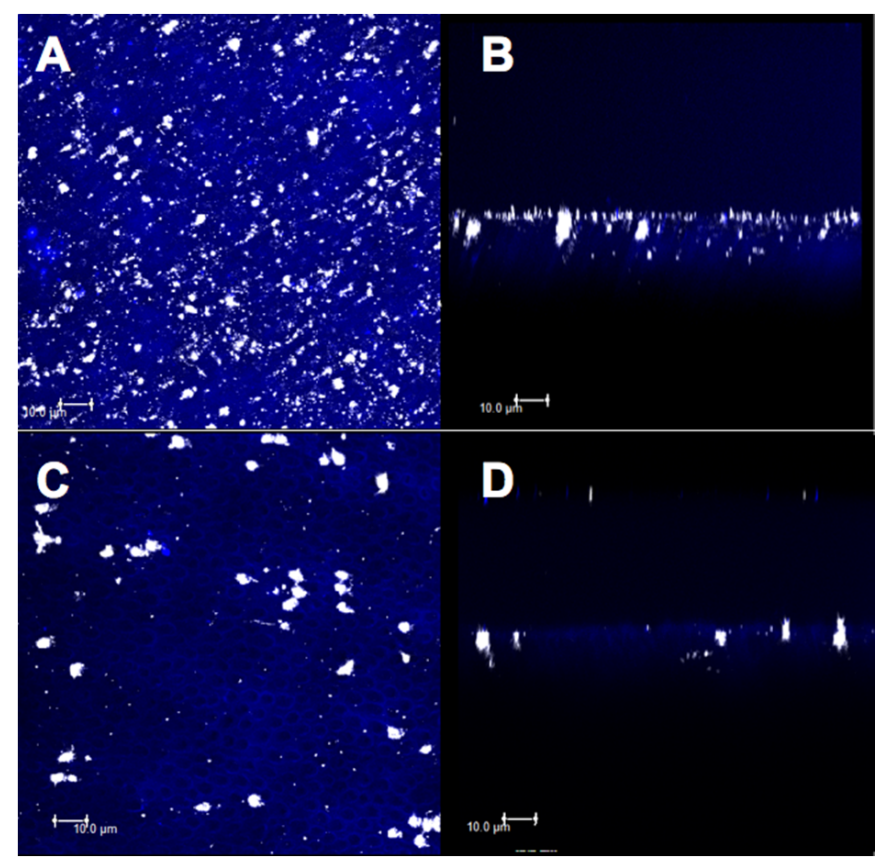

Figure 7. Confocal laser scanning microscopy images (fluorescence mode) in $X Y$ and $X Z$ axis of dentin surface. (A,B) With smear layer and $(\mathbf{C}, \mathbf{D})$ without smear layer.

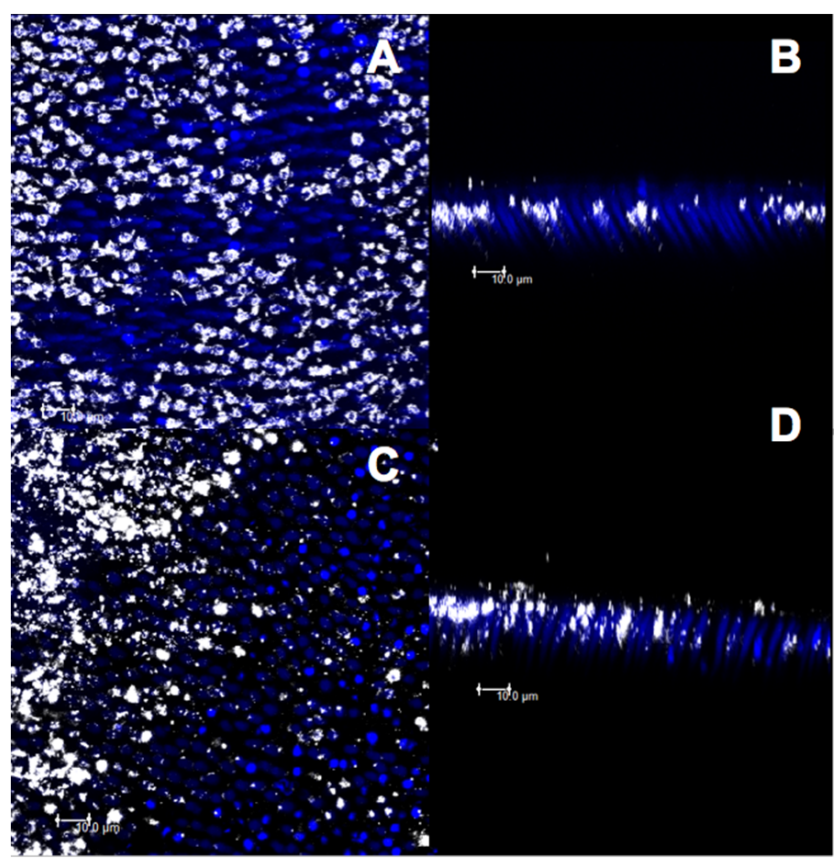

Figure 8. Confocal laser scanning microscopy images (fluorescence mode) in $X Y$ and $X Z$ axis of dentin surface. (A,B) Adhesive without nanofiber and (C,D) after 6\% citric acid challenge.

The images for group CN showed a higher deposition of material on the superficial dentin and a higher obliteration of the dentinal tubules (Figure 9A,B). However, after the acid challenge, a similarity was observed between the images of superficial (Figure 9C) and intratubular (Figure 9D) depositions.

After the treatment with group $\mathrm{D}$ and before the citric acid challenge, less deposition of the material on the dentin surface (Figure 10A) and less penetration of the varnish in the dentinal tubules (Figure 10B) were observed. After the acid challenge, the material remained deposited on the surface (Figure 10C) and inside the dentinal tubules 
(Figure 10D). However, the DN group showed a higher superficial deposition of the material (Figure 11A,C) as well as higher obliteration of dentinal tubules (Figure 11B,D), before and after the acid challenge.

Considering the results of the qualitative images of the different treatments proposed, it was observed that using the adhesive with nanofibers $(\mathrm{CN})$ presented larger superficial and intratubular depositions as compared to that in the other treatments.

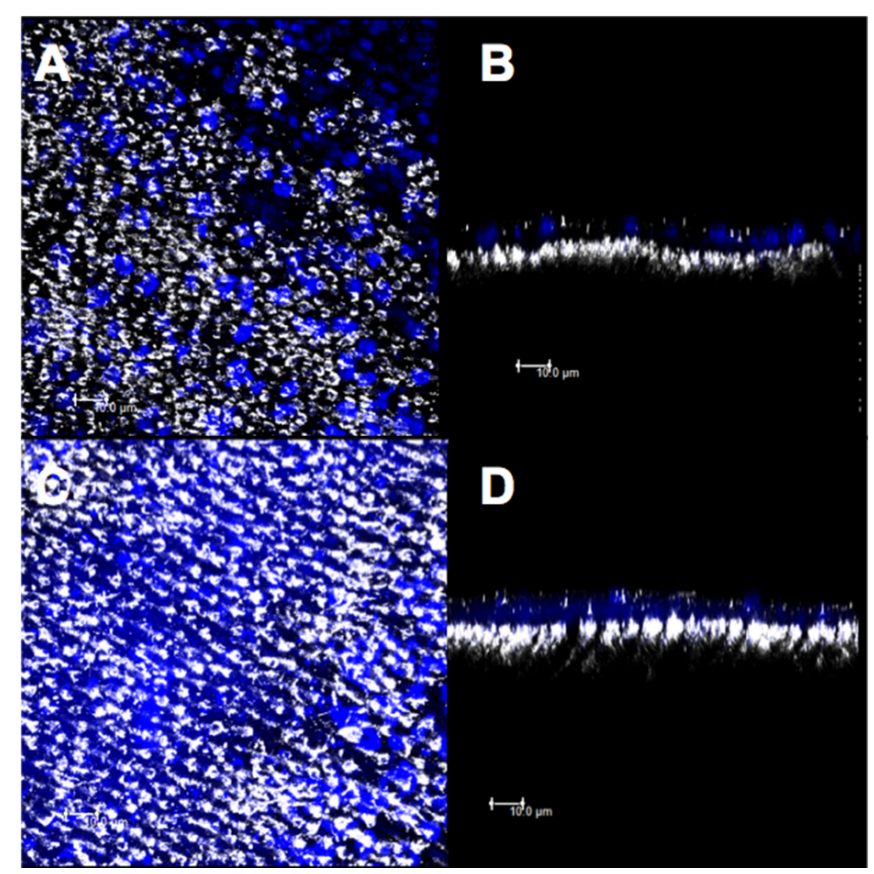

Figure 9. Confocal laser scanning microscopy images (fluorescence mode) in $X Y$ and $X Z$ axis of dentin surface. (A,B) Adhesive with nanofiber and (C,D) after $6 \%$ citric acid challenge.

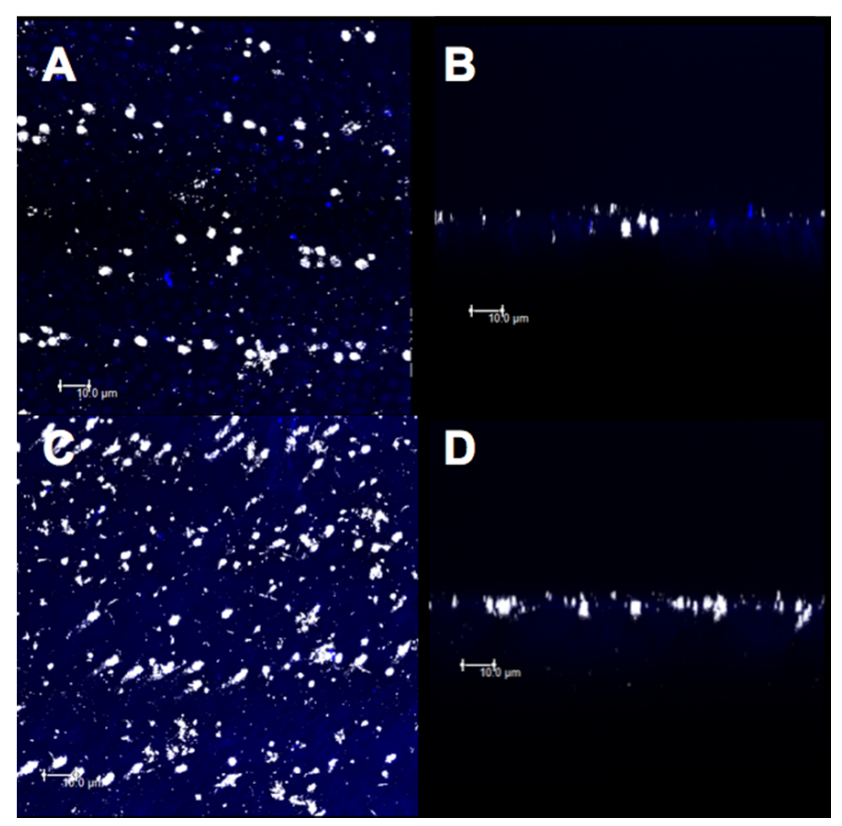

Figure 10. Confocal laser scanning microscopy images (fluorescence mode) in $X Y$ and $X Z$ axis of dentin surface. (A,B) Fluoride varnish without nanofiber and (C,D) after 6\% citric acid challenge. 


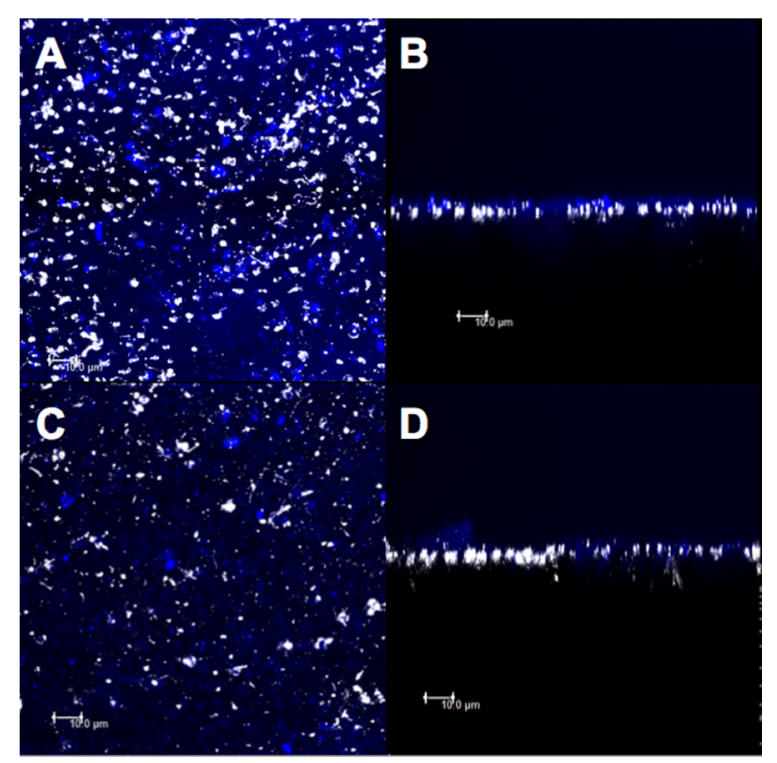

Figure 11. Confocal laser scanning microscopy images (fluorescence mode) in $X Y$ and $X Z$ axis of dentin surface. $(\mathbf{A}, \mathbf{B})$ Fluoride varnish with nanofiber and $(\mathbf{C}, \mathbf{D})$ after $6 \%$ citric acid challenge.

\section{Discussion}

One of the main issues of desensitizing agents is the instability of the occlusion [13], thus requiring at least 2-4 weeks to relieve the symptoms of DH [8]. Scaffolds of nanofibers may better spread the material in the dentinal tubules because the nanofibers might act as a carrier of the material into the dentinal tubules and have greater longevity due to the large surface area-to-volume ratio of the nanofibers [32], which could better react with the commercial materials used. Based on the results, the nanofibers could be successfully incorporated into the desensitizing agents because they have a higher potential for dentinal tubule obliteration (Figures 9B,D and 11B,D). Although the present study demonstrated that all the treatments had a similar effect on dentin permeability, the morphological changes in the dentin surfaces were observed in all the groups containing scaffolds of nanofibers. Therefore, the null hypothesis was accepted, since no Lp statistical difference was verified among all groups.

In the current study, we evaluated dental permeability using Flodec [30,33-35]. In this method, dentin permeability was measured through the movement of dentinal fluids and calculated by Lp\% values [34]. The effectiveness of the desensitizing agents was evaluated when the $\mathrm{Lp} \%$ values were similar to those obtained in the presence of the smear layer, representing minimum permeability [34]. Our results showed that only group D presented a dentin permeability similar to the minimum permeability, which can be explained by the mechanical barrier created by $\mathrm{CaF}_{2}$ precipitation on the dental surface $[13,36]$ and the ability to form a reservoir of $\mathrm{CaF}_{2}$ due to high fluoride concentration [37]. In addition, the $\mathrm{F}$ varnish may have created a more stable crystallization retention inside the dentinal tubules, as shown in a previous study [34]. This mechanical barrier affects the dentin permeability and DH [38]; however, the short duration of the anti-hyperesthesia effect is still a challenge [39].

The SEM micrographs of the dentin surface showed that the DN group (Figure 6A,B) presented a more obliterated dentin surface than group $D$ (Figure $5 A, B$ ), even after the acid challenge. In addition, the DN group demonstrated higher deposition of crystals in the wall and mouth (Figure 5B), although the partial occlusion of the dentinal tubules in group DN (Figure 6B) was similar to that of group D (Figure 5B). The higher obliteration of the dentinal tubules in the group containing the nanofibers can be explained by the formation of an HAP-like layer by the presence of silica, since silica-based bioactive glasses can react with saliva and HAP-like layers $[15,40]$. Further research using these modified 
desensitizers is needed to prove if the particles formed represent HAP-like layers and present bioactivity by simulating body fluid analysis.

The topical application of self-etching adhesives has been used to manage DH [41,42]. For better adherence to dentin over dentin desensitizers [13], the present design also evaluated the effect of nanofiber incorporation into self-adhesives. Although the permeabilities of all the groups were similar, the morphological changes were observed on the dentin surfaces for group $\mathrm{CN}$ since it (Figure $4 \mathrm{~A}, \mathrm{~B}$ ) showed a more homogeneous and uniform surface with a higher dentinal tubule occlusion as compared to those of group $C$ (Figure $3 \mathrm{~A}, \mathrm{~B}$ ), before and after the acid challenge. This can be attributed to the self-etching adhesives producing an acid-resistant hybrid layer [43]. The presence of silica also contributed to the formation of a more homogeneous surface due to the higher intratubular deposition of the material (Figure 9B,D). These results are relevant because the incorporation of these nanofibers could improve the mechanical resistance of the desensitizing agents after new erosion challenges. The enhanced mechanical resistance of these modified materials makes them promising desensitizing agents for long-term action. To the best of our knowledge, only one study has incorporated hybrid nanofibers into dental materials and showed improved mechanical properties of resin-based cement [20], which could strengthen this hypothesis; however, further studies are required to confirm this.

The release of therapeutic ions $\left(\mathrm{Sr}^{+2}, \mathrm{Ag}^{+}, \mathrm{Fe}^{+2}, \mathrm{~F}^{-1}\right.$, and $\left.\mathrm{Cu}^{+}\right)$from inorganic-organic hybrid nanofibers encourages the use of nanofibers in the engineering of dental materials [44]. Silica-based bioactive nanofibers have been widely used for biomedical applications [45]. The addition of silica at the nanoscale within the nanofibers used in this study may increase the adherence to calcium phosphate present in dentin due to the increase in the surface area-to-volume ratio [22,24]. Moreover, the formation of an insoluble HAP-like layer is expected. Confocal analysis was effective in evaluating the obliteration of the dentinal tubules because bright spots in dentinal tubules were found that corresponded to either the smear layer or the materials used in this study. Both the desensitizing agents with nanofibers, i.e., $\mathrm{CN}$ and $\mathrm{DN}$, showed a higher deposition of the material in the superficial dentin (Figures $8 \mathrm{~A}, \mathrm{C}$ and $11 \mathrm{~A}, \mathrm{C}$ ) and a higher obliteration of the dentinal tubules (Figures $8 \mathrm{~B}, \mathrm{D}$ and $11 \mathrm{~B}, \mathrm{D}$ ), thus indicating that the nanoscale silica may have facilitated the penetration of the experimental material. However, the $\mathrm{CN}$ group demonstrated a higher obliteration as compared to that of the DN group, since the resin matrix of the adhesive system may have shown better intramolecular hydrogen bonds with the nanofibers due to the surface area to volume ratio [32]. This facilitated penetration into the dentinal tubes. In addition, clusters of nanofibers may have been formed, thus making it difficult for the varnish to penetrate the dentin surface.

Although the addition of the nanofibers into desensitizing agents showed no statistical difference in $\mathrm{Lp} \%$, more tubular obliterations were found for the nanofiber groups. Such results make nanofibers attractive compounds for use in desensitizing agents for treating dentin hypersensitivity, especially after the acid challenge where the material remained deposited on the surface. Considering that nanofibers have also shown great mechanical properties in the dental materials field [20,29], it could be used as mechanical barrier in further acid challenges in remineralizing products such as dentifrices, varnishes, and adhesives to inhibit erosion development and progression in a long-term performance. However, the choice of desensitizing agents is not important to determine the patient's predisposing factors [46] to the risk of dentin exposure [47]. The thickness and shape of the specimens and the absence of enamel and pulp horn from the specimens analyzed in this study limit the clinical significance of the findings of this study. In addition, the comparison of different percentages of nanofiber addition into these materials could promote different results. Additionally, dentin permeability measurements require the prior application of $37 \%$ phosphoric acid before the application of treatments and this fact does not simulate clinical conditions; however, this limitation can be overcome in future research with the use of other methods for assessing dentin permeability or through clinical research that does not involve this step. To validate the results obtained in this study, further research should 
be conducted to analyze the clinical performance of scaffold nanofibers in desensitizing agents, so that the symptoms of DH may also be assessed. Additionally, the obliteration action of nanofibers should be further compared to bioactive glass particles as it represents the gold standard in bone regenerative repair and possesses excellent bioactivity [21].

\section{Conclusions}

Based on the results, although all treatments had similar permeabilities, the desensitizing agents with nanofibers were potentially effective as occlusive agents based on qualitative analysis. Further studies to investigate the effect of nanofiber-based desensitization in the clinical scenario are recommended.

Author Contributions: In regard to the contributions of each author, all authors contributed equally to the work. N.B.-B., M.V., M.G.d.F. and T.N. participated in the concepts and coordination of the study, performed the study design, and drafted the manuscript. C.S., S.I., M.G.d.F. and J.B. conceived the study, fabricated the samples, and participated in assays, as well helped draft the manuscript. L.G., L.C. and S.S. per-formed the statistical analysis and participated in interpretation of the data. All authors have read and agreed to the published version of the manuscript.

Funding: This research was funded by the Brazilian National Council for Scientific and Technological Development (CNPq) —Grant/Award Number: 142082/2018-0.

Institutional Review Board Statement: This manuscript is an in vitro research with human third molars and informed consent was obtained under a protocol approved by the Ethics Committee of Bauru School of Dentistry, University of Sao Paulo (Protocol/90548918.9.0000.5417).

Informed Consent Statement: Not applicable.

Data Availability Statement: Data sharing is not applicable to this article.

Conflicts of Interest: The authors declare no conflict of interest.

\section{References}

1. Markowitz, K.; Pashley, D.H. Discovering new treatments for sensitive teeth: The long path from biology to therapy. J. Oral Rehabil. 2008, 35, 300-315. [CrossRef] [PubMed]

2. Que, K.; Guo, B.; Jia, Z.; Chen, Z.; Yang, J.; Gao, P. A cross-sectional study: Non-carious cervical lesions, cervical dentine hypersensitivity and related risk factors. J. Oral Rehabil. 2012, 40, 24-32. [CrossRef]

3. West, N.; Seong, J.; Davies, M. Dentine Hypersensitivity. Oral Biofilms 2014, 25, 108-122.

4. Brannstrom, M.; Linden, L.-A.; Johnson, G. Movement of Dentinal and Pulpal Fluid Caused by Clinical Procedures. J. Dent. Res. 1968, 47, 679-682. [CrossRef] [PubMed]

5. Pashley, D.H. Dentine permeability and its role in the pathobiology of dentine sensitivity. Arch. Oral Biol. 1994, 39, S73-S80. [CrossRef]

6. Liang, K.; Xiao, S.; Liu, H.; Shi, W.; Li, J.; Gao, Y.; He, L.; Zhou, X.; Li, J. 8DSS peptide induced effective dentinal tubule occlusion in vitro. Dent. Mater. 2018, 34, 629-640. [CrossRef] [PubMed]

7. Miglani, S.; Aggarwal, V.; Ahuja, B. Dentin hypersensitivity: Recent trends in management. J. Conserv. Dent. 2010, 13, $218-224$. [CrossRef]

8. Lynch, E.; Brauer, D.S.; Karpukhina, N.; Gillam, D.G.; Hill, R.G. Multi-component bioactive glasses of varying fluoride content for treating dentin hypersensitivity. Dent. Mater. 2012, 28, 168-178. [CrossRef]

9. Cummins, D. Recent advances in dentin hypersensitivity: Clinically proven treatments for instant and lasting sensitivity relief. Am. J. Dent. 2010, 23.

10. Ritter, A.V.; De Dias, W.L.; Miguez, P.A.; Caplan, D.J; Swift, E.J. Treating cervical dentin hypersensitivity with fluoride varnish. J. Am. Dent. Assoc. 2006, 137, 1013-1020. [CrossRef]

11. Castillo, J.L.; Milgrom, P. Fluoride release from varnishes in two in vitro protocols. J. Am. Dent. Assoc. 2004, 135, 1696-1699. [CrossRef]

12. Yu, X.; Liang, B.; Jin, X.; Fu, B.; Hannig, M. ComparativeIn VivoStudy on the Desensitizing Efficacy of Dentin Desensitizers and One-bottle Self-etching Adhesives. Oper. Dent. 2010, 35, 279-286. [CrossRef]

13. Orchardson, R.; Gillam, D.G. Managing dentin hypersensitivity. J. Am. Dent. Assoc. 2006, 137, 990-998. [CrossRef]

14. Du Min, Q.; Bian, Z.; Jiang, H.; Greenspan, D.C.; Burwell, A.K.; Zhong, J.; Tai, B.J. Clinical evaluation of a dentifrice containing calcium sodium phosphosilicate (novamin) for the treatment of dentin hypersensitivity. Am. J. Dent. 2008, 21, 210-214. [PubMed] 
15. Lopez, T.C.C.; Diniz, I.M.A.; Ferreira, L.S.; Marchi, J.; Borges, R.; De Cara, S.P.H.M.; D'Almeida-Couto, R.; Marques, M.M. Bioactive glass plus laser phototherapy as promise candidates for dentine hypersensitivity treatment. J. Biomed. Mater. Res. Part B Appl. Biomater. 2015, 105, 107-116. [CrossRef] [PubMed]

16. Singh, R.K.; Jin, G.-Z.; Mahapatra, C.; Patel, K.D.; Chrzanowski, W.; Kim, H.-W. Mesoporous Silica-Layered Biopolymer Hybrid Nanofibrous Scaffold: A Novel Nanobiomatrix Platform for Therapeutics Delivery and Bone Regeneration. Acs Appl. Mater. Interfaces 2015, 7, 8088-8098. [CrossRef] [PubMed]

17. Bonan, R.F.; Bonan, P.R.; Batista, A.U.; Sampaio, F.C.; Albuquerque, A.J.; Moraes, M.C.; Mattoso, L.H.; Glenn, G.M.; Medeiros, E.S.; Oliveira, J.E. In vitro antimicrobial activity of solution blow spun poly(lactic acid)/polyvinylpyrrolidone nanofibers loaded with Copaiba (Copaifera sp.) oil. Mater. Sci. Eng. C 2015, 48, 372-377. [CrossRef] [PubMed]

18. Blaker, J.J.; Knowles, J.C.; Day, R.M. Novel fabrication techniques to produce microspheres by thermally induced phase separation for tissue engineering and drug delivery. Acta Biomater. 2008, 4, 264-272. [CrossRef]

19. De Oliveira, A.A.R.; Gomide, V.S.; Leite, M.D.F.; Mansur, H.S.; Pereira, M.D.M. Effect of polyvinyl alcohol content and after synthesis neutralization on structure, mechanical properties and cytotoxicity of sol-gel derived hybrid foams. Mater. Res. 2009, 12, 239-244. [CrossRef]

20. Velo, M.M.; Nascimento, T.R.; Scotti, C.K.; Bombonatti, J.F.; Furuse, A.Y.; Silva, V.D.; Simões, T.A.; Medeiros, E.S.; Blaker, J.J.; Silikas, N.; et al. Improved mechanical performance of self-adhesive resin cement filled with hybrid nanofibers-embedded with niobium pentoxide. Dent. Mater. 2019, 35, e272-e285. [CrossRef]

21. Ding, Y.; Li, W.; Müller, T.; Schubert, D.W.; Boccaccini, A.R.; Yao, Q.; Roether, J.A. Electrospun Polyhydroxybutyrate/Poly ( $\varepsilon$-caprolactone)/58S Sol-Gel Bioactive Glass Hybrid Scaffolds with Highly Improved Osteogenic Potential for Bone Tissue Engineering. Acs Appl. Mater. Interfaces 2016, 8, 17098-17108. [CrossRef]

22. Fedorova, N.; Pourdeyhimi, B. High strength nylon micro- and nanofiber based nonwovens via spunbonding. J. Appl. Polym. Sci. 2007, 104, 3434-3442. [CrossRef]

23. Keul, C.; Liebermann, A.; Roos, M.; Uhrenbacher, J.; Stawarczyk, B. The effect of ceramic primer on shear bond strength of resin composite cement to zirconia. J. Am. Dent. Assoc. 2013, 144, 1261-1271. [CrossRef] [PubMed]

24. Hunley, M.T.; Long, T.E. Electrospinning functional nanoscale fibers: A perspective for the future. Polym. Int. 2008, 57, 385-389. [CrossRef]

25. Carvalho, A.S.; Cury, J.A. Fluoride release from some dental materials in different solutions. Oper. Dent. 1999, $24,14-19$.

26. Kolbasov, A.; Sinha-Ray, S.; Joijode, A.; Hassan, M.A.; Brown, D.B.; Maze, B.; Pourdeyhimi, B.; Yarin, A.L. Industrial-Scale Solution Blowing of Soy Protein Nanofibers. Ind. Eng. Chem. Res. 2016, 55, 323-333. [CrossRef]

27. Polat, Y.; Pampal, E.S.; Stojanovska, E.; Simsek, R.; Hassanin, A.H.; Kilic, A.R.; Demir, A.; Yilmaz, S. Solution blowing of thermoplastic polyurethane nanofibers: A facile method to produce flexible porous materials. J. Appl. Polym. Sci. 2016, 133, 133. [CrossRef]

28. Sinha-Ray, S.; Sinha-Ray, S.; Yarin, A.L.; Pourdeyhimi, B. Theoretical and experimental investigation of physical mechanisms responsible for polymer nanofiber formation in solution blowing. Polymer 2015, 56, 452-463. [CrossRef]

29. Nascimento, T.R.D.L.; Velo, M.M.D.A.C.; Silva, C.F.; Cruz, S.B.S.C.; Gondim, B.L.C.; Mondelli, R.F.L.; Castellano, L.R.C. Current Applications of Biopolymer-based Scaffolds and Nanofibers as Drug Delivery Systems. Curr. Pharm. Des. 2019, 25, $3997-4012$. [CrossRef] [PubMed]

30. Rusin, R.P.; Agee, K.; Suchko, M.; Pashley, D.H. Effect of a new desensitizing material on human dentin permeability. Dent. Mater. 2010, 26, 600-607. [CrossRef] [PubMed]

31. Sauro, S.; Watson, T.F.; Thompson, I. Dentine desensitization induced by prophylactic and air-polishing procedures: An in vitro dentine permeability and confocal microscopy study. J. Dent. 2010, 38, 411-422. [CrossRef]

32. Tian, M.; Gao, Y.; Liu, Y.; Liao, Y.; Xu, R.; Hedin, N.E.; Fong, H. Bis-GMA/TEGDMA dental composites reinforced with electrospun nylon 6 nanocomposite nanofibers containing highly aligned fibrillar silicate single crystals. Polymer 2007, 48, 2720-2728. [CrossRef] [PubMed]

33. Wang, L.; Magalhães, A.C.; Francisconi-Dos-Rios, L.F.; Calabria, M.P.; Araújo, D.; Buzalaf, M.; Lauris, J.; Pereira, J.C. Treatment of Dentin Hypersensitivity Using Nano-Hydroxyapatite Pastes: A Randomized Three-Month Clinical Trial. Oper. Dent. 2016, 41, E93-E101. [CrossRef] [PubMed]

34. Calabria, M.; Porfirio, R.; Fernandes, S.; Wang, L.; Buzalaf, M.; Pereira, J.; Magalhães, A. Comparative In Vitro Effect of TiF4 to $\mathrm{NaF}$ and Potassium Oxalate on Reduction of Dentin Hydraulic Conductance. Oper. Dent. 2014, 39, 427-432. [CrossRef] [PubMed]

35. Hiller, K.-A.; Buchalla, W.; Grillmeier, I.; Neubauer, C.; Schmalz, G. In vitro effects of hydroxyapatite containing toothpastes on dentin permeability after multiple applications and ageing. Sci. Rep. 2018, 8, 4888. [CrossRef]

36. Davari, A.; Ataei, E.; Assarzadeh, H. Dentin Hypersensitivity: Etiology, Diagnosis and Treatment; A Literature Review. J. Dent. 2013, 14, 136-145.

37. Cate, J.M.T. Review on fluoride, with special emphasis on calcium fluoride mechanisms in caries prevention. Eur. J. Oral Sci. 1997, 105, 461-465. [CrossRef]

38. Gaffar, A. Treating hypersensitivity with fluoride varnishes. Compend. Contin. Educ. Dent. (Jamesburg, N.J. 1995) 1998, 19, 1088-1090. 
39. Yilmaz, H.G.; Kurtulmus-Yilmaz, S.; Cengiz, E. Long-Term Effect of Diode Laser Irradiation Compared to Sodium Fluoride Varnish in the Treatment of Dentine Hypersensitivity in Periodontal Maintenance Patients: A Randomized Controlled Clinical Study. Photomed. Laser Surg. 2011, 29, 721-725. [CrossRef]

40. Zhong, Y.; Liu, J.; Li, X.; Yin, W.; He, T.; Hu, D.; Liao, Y.; Yao, X.; Wang, Y. Effect of a novel bioactive glass-ceramic on dentinal tubule occlusion: Anin vitrostudy. Aust. Dent. J. 2014, 60, 96-103. [CrossRef]

41. Canali, G.D.; Ignacio, S.A.; Rached, R.N.; Souza, E.M. Clinical efficacy of resin-based materials for dentin hypersensitivity treatment. Am. J. Dent 2017, 30, 201-204. [PubMed]

42. Osmari, D.; Fraga, S.; de Ferreira, A.C.O.; de Eduardo, C.P.; Marquezan, M.; Silveira, B.L. da In-office Treatments for Dentin Hypersensitivity: A Randomized Split-mouth Clinical Trial. Oral Health Prev. Dent. 2018, 16, 125-130. [CrossRef] [PubMed]

43. Tsuchiya, S.; Nikaido, T.; Sonoda, H.; Foxton, R.M.; Tagami, J. Ultrastructure of the dentin-adhesive interface after acid-base challenge. J. Adhes Dent. 2004, 6, 183-190. [PubMed]

44. Hoppe, A.; Mouriño, V.; Boccaccini, A.R. Therapeutic inorganic ions in bioactive glasses to enhance bone formation and beyond. Biomater. Sci. 2012, 1, 254-256. [CrossRef]

45. Lu, H.; Zhang, T.; Wang, X.P.; Fang, Q.F. Electrospun submicron bioactive glass fibers for bone tissue scaffold. J. Mater. Sci. Mater. Med. 2009, 20, 793-798. [CrossRef]

46. Shiau, H.J. Dentin Hypersensitivity. J. Evid. Based Dent. Pract. 2012, 12, 220-228. [CrossRef]

47. Marto, C.M.; Paula, A.B.; Nunes, T.; Pimenta, M.; Abrantes, A.M.; Pires, A.S.; Laranjo, M.; Coelho, A.; Donato, H.; Botelho, M.F.; et al. Evaluation of the efficacy of dentin hypersensitivity treatments-A systematic review and follow-up analysis. J. Oral Rehabil. 2019, 46, 952-990. [CrossRef] 